\title{
Cocculus hirsutus Trypsin Inhibitor Confers Resistance to Ralstonia solanacearum: In silico Analysis
}

\author{
Manushree $\mathrm{V}^{1,2}$, Udit $\mathrm{NM}^{1,3}$, Manjunath $\mathrm{BJ}^{1}$, Devaraj $\mathrm{VR}^{2}$ and Theertha \\ Prasad D ${ }^{1 *}$ \\ ${ }^{1}$ Department of Plant Biotechnology, University of Agricultural Sciences, GKVK, \\ Bangalore, India \\ ${ }^{2}$ Department of Biochemistry, Bangalore University, Central College Campus, \\ Bangalore, India. \\ ${ }^{3}$ Department of Biochemistry and Crop physiology, MS Swaminathan School of \\ Agriculture, Centurion University of Technology and management, Paralakhemundi, \\ Odisha, India. \\ *Corresponding Author: D Theertha Prasad, Professor, Department of Plant \\ Biotechnology, University of Agricultural Sciences, GKVK, Bangalore, India.
}

\author{
Received: April 08, 2020 \\ Published: May 13, 2020 \\ (C) All rights are reserved by Manushree., \\ et al.
}

\begin{abstract}
Genetic engineering has proven to be an efficient strategy for the development of Disease resistant crops. Gram negative bacteria Ralstonia solanacearum, the causative agent of wilt has been causing devastating economic losses in tomato crop yield worldwide. In this study Cocculus hirsutus trypsin inhibitor has demonstrated for its bactericidal activity. Transgenic plants expressing ChTI were developed conferring resistance to Gram negative bacteria, particularly R. solanacearum. In vitro and In vivo studies revealed the bactericidal activity of ChTI with mortality rate upto $42 \%$ and $48 \%$ in E. coli and $R$. solanacearum at 500 TIU/mg respectively. Transgenic plants expressing ChTI also developed resistance to the wilt. Whereas non transgenic plants developed symptoms of the disease. Further Strong interaction patterns of ChTI-Lipid and ChTI-membrane proteins revealed the possible mechanism of action of these PIs. These results demonstrate the effectiveness of ChTI as bactericidal agent and is able to enhance resistance in transgenic plants against bacterial pathogens.
\end{abstract}

Keywords: R. Solanacearum; Cell Membrane Binding Protein; Cocculus hirsutus Trypsin Inhibitor; Evans Blue Assay; Spot Dilution Bacterial Assay; In Silico Protein-Lipid Interactions

\section{Abbreviations}

LB: Luria-Bertani; TZC: 2,3,5-Triphenyl Tetrazolium Chloride; TLA: Trypsin Like Activity; TIA: Trypsin Inhibitory Activity; TIU: Trypsin Inhibitory Units; TU: Trypsin Units; MIC: Minimum Inhibitory Concentration

\section{Introduction}

Multitudinous factors are responsible for the bacterial pathogenesis development, among which proteinases play a pivotal role. Contribution of some conserved proteinases, to the pathogenesis, has been reported in both gram positive and negative bacteria. Conserved proteinase domains in gram positive bacteria control the virulence factor production, whereas proteinase in gram negative bacteria alter the biological process across the bacterial envelope thus contribute to host cell infection [1]. Many gram negative bacterial pathogens use type III secretion system to inject viru- lence factors to induce pathogenesis in host cell. Pseudomonas syringae is known to inject AvrRpt2 protease to promote pathogen virulence [2,3]. P. syringae uses a different strategy, secret serine proteinases AvrA which misguides the plant flagellin mediated immune response in tomato [4]. Bacteria are known to secret proteinases to degrade cell wall components that make their way to enter plant cell. Prt1 isolated from Pectobacterium carotovorum was able to degrade potato lectin [5] and Yop J proteinases target plant hormone system interfering with the jasmonic acid and salicylic acid signalling pathway, by attenuating the expression of defence response genes [6-8].

Plants up-regulate number of genes which include antimicrobial peptides (AMPs) which are distributed in all plant tissues. They are the primary components of defence barrier in plants and show lethal effects on different microorganisms. AMPs are cationic, amphipathic, with helical structure having broad spectrum anti- 
microbial activity. Plant AMPs are grouped based on the sequence homology and mode of action into defensins, thionins, lipid transfer proteins, cyclotides, snakins and hevein-like proteins [9]. These molecules target microbes at extracellular levels through receptor or non-receptor mediated interactions and intracellular host immune system modulation [10]. Proteinase inhibitors, isolated from various plant sources, are found successful in inhibiting the growth of phytopathogens. PIs extracted from leaves of Coccinia grandis showed antibacterial activity against Staphylococcus aureus, Proteus vulgaris [11]. PI from seeds of Lavatera cashmeriana inhibited the growth of Klebsiella pneumoniae and Pseudomonas aeruginosa [12]. PIs have gained major attention in clinical field as potent antibiotics $[13,14]$, anti-carcinogenic agents $[15,16]$ and therapeutic drugs $[17,18]$. Considering the importance of PIs in medicine and in agriculture as biocontrol agents, potentiality of serine proteinase Inhibitor, ChTI [19] was evaluated.

\section{Material and Methods}

Extraction of inhibitor from transgenic tomato plants expressing ChTI

Transgenic tomato plants harbouring ChTI was developed conferring resistance to Helicoverpa armigera. Resistant lines were selected based on PCR, expression of ChTI, inhibitory activity and in gel activity assay [20]. Leaf acetone powder from positive plants was stirred in extraction buffer $(1: 5 \mathrm{w} / \mathrm{v} ; 50 \mathrm{Mm}$ Tris- $\mathrm{HCl}, 50 \mathrm{mM}$ EDTA, $25 \mathrm{mM}$ ascorbic acid and $10 \mathrm{mM} \beta$-mercaptoethanol at $\mathrm{pH}$ 7.4 ), centrifuged at $12,000 \mathrm{rpm}$ for 20 minutes at $4^{\circ} \mathrm{C}$. The supernatant was incubated at $70^{\circ} \mathrm{C}$ for 10 minutes; snap chilled, centrifuged at $12,000 \mathrm{rpm}$ for 20 minutes at $4^{\circ} \mathrm{C}$ to get Heat soluble proteins (HSPs). ChTI in HSPs was purified using trypsin sepharose affinity column and assayed for trypsin inhibitory as well as antibacterial activity.

\section{In vitro antibacterial assay}

Logarithmic phase bacterial cultures were assessed on different concentrations of ChTI (100 - 1500 TIU). Bacterial cultures were grown in LB (E. coli) and TZC (R. solanacearum) media to a density of $1.5 \times 10^{5}$ cells $/ \mathrm{ml}$ and were incubated with different concentrations of $\mathrm{ChTI}$ for $2 \mathrm{~h}$ at $37^{\circ} \mathrm{C}$. Serial dilutions up to a final density of $1.5 \times 10^{1}$ cells $/ \mathrm{ml}$ were performed. Five $\mu$ of each was spotted on agar plates and incubated at $37^{\circ} \mathrm{C}$. Growth pattern was observed after $18 \mathrm{~h} .500 \mu \mathrm{l}$ cell suspensions were incubated with $0.1 \%$, Evan's blue dye (w/v, $0.1 \mathrm{~g}$ in $100 \mathrm{ml}$ ethanol) for $1 \mathrm{~h}$ at $37^{\circ} \mathrm{C}$, Percent mortality of cells was assessed by measuring the bound dye. Bacterial suspensions incubated with distilled water and nontransgenic tomato extracts were taken as control.
Trypsin like activity

R. solanacearum/E. coli culture was grown till late log phase or early stationary phase. Cells were pelleted by spinning at 6000 rpm for 10 minutes, cells were suspended in $10 \mathrm{mM}$ Tris buffer $\mathrm{pH}$ 7.4 and sonicated for 10 minutes. Cell pellets were washed several times with $10 \mathrm{mM}$ Tris buffer $\mathrm{pH} 7.4$ before stirred in same buffer containing $0.2 \%$ TritonX-100 for 20 minutes at $4{ }^{\circ} \mathrm{C}$, spinned down at $12000 \mathrm{rpm}$ for 5 minutes at $4^{\circ} \mathrm{C}$. The supernatant obtained was washed thrice with 5 volumes of ice cold ethanol and $2 \%$ acetic acid and finally dissolved in $10 \mathrm{mM}$ Tris buffer $\mathrm{pH} 7.4$ with $0.2 \%$ TritonX-100. TLA/TIA was assayed as per the method described by Kunitz casein digestion method [19,20].

\section{Binding studies of bacterial cell membrane protein}

Trypsin inhibitor affinity column was prepared as per protocols of March., et al. [21] with slight modifications. $20 \mathrm{ml} \mathrm{CNBr}$ activated sepharose 4B slurry was washed with $150 \mathrm{ml}$ of $100 \mathrm{mM}$ sodium bicarbonate $(\mathrm{pH}-8.5)$ repeatedly for several times. After a brief water wash, the slurry was stirred with $50 \mathrm{mg} / \mathrm{ml}$ of ChTI solution for $20 \mathrm{~h}$ at $4^{\circ} \mathrm{C}$. Unbound inhibitor was removed by washing with bicarbonate buffer and stirred with $300 \mathrm{mg}$ of glycine, to mask unreacted groups if present. The slurry was washed with double distilled water several times till neutral $\mathrm{pH}$ and suspended in $100 \mathrm{mM}$ potassium phosphate buffer ( $\mathrm{pH}$ 7.6). The column was saturated with repeated application of bacterial cell wall proteins, column was thoroughly washed to remove unbound proteins and cell wall protein bound fraction was eluted with $2 \%$ SDS. The eluted fractions were analysed on SDS-PAGE followed by western blot using anti ChTI-IgY.

In situ evaluation of ChTI transgenic plants against $R$. solanacearum

Transgenic Plant response to R. solanacearum was assayed with 25 days seedlings. The roots of both control (non-transformed) and ChTI expressing transgenic tomato plants were inoculated with $1 \mathrm{x}$ $10^{5} \mathrm{CFU} / \mathrm{ml}$ bacterial suspension, the roots of which were injured prior to inoculation. Minimum of triplicate samples were maintained in each treatment. Disease incidence was evaluated weekly and scaled according to infection, 0 (no wilting) - 4 (wilted dead plant).

In silico analysis of ChTI interactions with cell membrane proteins of $R$. solanacearum

ChTI protein sequence (NCBI No: EF207318) was deduced using BLASTp program. HDOCK [22] was used to examine proteinprotein interaction and protein - lipid interaction with ChTI and phospholipid binding protein (PLP) from $R$. solanacearum (PDB ID: 2QGU) and Di-Palmitoy-3-Sn-Phosphatidylethanolamine. A total of 
100 low energy ChTI-PLP structures were generated. Using information on conserved residues, docking scores and ligand RMSD as main criteria, interacting models were filtered. Data on interacting residues was generated using the DIMPLOT tool [23] and complex was analysed using PyMOL1.3 [24].

\section{Results}

In vitro evaluation of transgene ChTI against bacterial pathogens

Tomato transgenic leaf extracts (ChTI) were evaluated for antibacterial activity by serial dilution and Evans blue test (Figure 1). Reduction in E. coli growth was initiated at $500 \mathrm{TIU} / \mathrm{ml}$ and at $1500 \mathrm{TIU} / \mathrm{ml}$ caused complete reduction in growth. The results of Evan's blue dye binding assay is also on par with this result (Figure 1C). TLA activity of $E$. coli, $350.0 \pm 5.0 \mathrm{TU}(100 \mu \mathrm{g}$ protein per $\mathrm{ml}$ ) reduced to $42 \%$ in presence of $500 \mathrm{TIU} / \mathrm{ml}$ of ChTI, with an $\mathrm{IC}_{50}$ of 800 TIU. The result of the effect of ChTI on $R$. solanacearum showed growth reduction in ChTI treated bacterial suspensions ranging from 500 - 1500 TIU/ml (Figure 2A). Further Evan's blue assay indicated a mortality rate of $42 \%$ in cell suspensions with 500 TIU (ChTI) which enhanced to $74 \%$ at 1500.0 TIU (ChTI) (Figure 2B). Trypsin like activity of bacterial cell wall extract was 473.4 $\pm 3.44(100$ protein $\mu \mathrm{g} / \mathrm{ml})$, reduced to $48 \%$ in presence of 500 $\mathrm{TIU} / \mathrm{ml}$ of ChTI, with an IC ${ }_{50}$ value of $550.0 \mathrm{TIU}$.

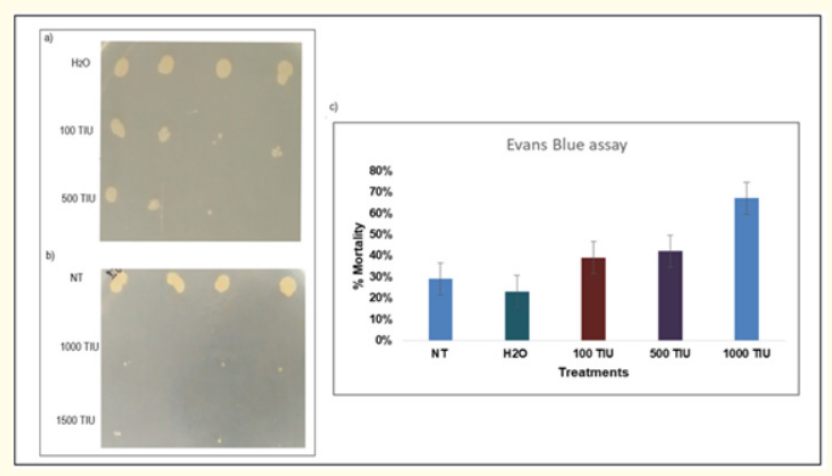

Figure 1: In vitro evaluation of bactericidal activity of ChTI against E. coli: Serial dilution assay was carried out to test the bactericidal activity of ChTI. a and b) Different concentrations of ChTI 100 1500 TIU was incubated with $E$. coli cells (10-1 - 10-3). Water and non- transgenic plant extracts were used as control. c) The above mixture was incubated with Evan's blue dye for $2 \mathrm{~h}$ resulting in the correlation of results of serially dilution assay and Evan's blue assay. MIC was recorded at 100 TIU with $34 \%$ mortality rate.

\section{Membrane protein binding assay}

Membrane proteins bound to ChTI - sepharose column was eluted with $2 \%$ SDS and was separated on SDS-PAGE gels (Fig- ure 2B). Protein bands of about $50 \mathrm{kDa}$ were visualised from Coomassie brilliant blue staining. Western blot analysis with ChTI-IgY showed reactivity with eluted cell membrane protein, suggest the possible interaction of cell membrane proteins with ChTI (Figure $2 \mathrm{c}$ and $2 \mathrm{~d}$ ).

Bioevaluation of transgenic tomato plants against $R$. solanacearum

Transgenic tomato plants were used to evaluate whether ChTI would confer resistance to $R$. solanacearum. The wilting symptoms was measured every 5 days for 30 days. In non-transgenic plants, symptoms of the disease were observed after 11 days of infection (Figure 2e-4) and subsequently plant showed complete mortality. Transgenic plants were healthy with hardly any symptoms of wilt caused by R. solanacearum (Figure 2e-3).

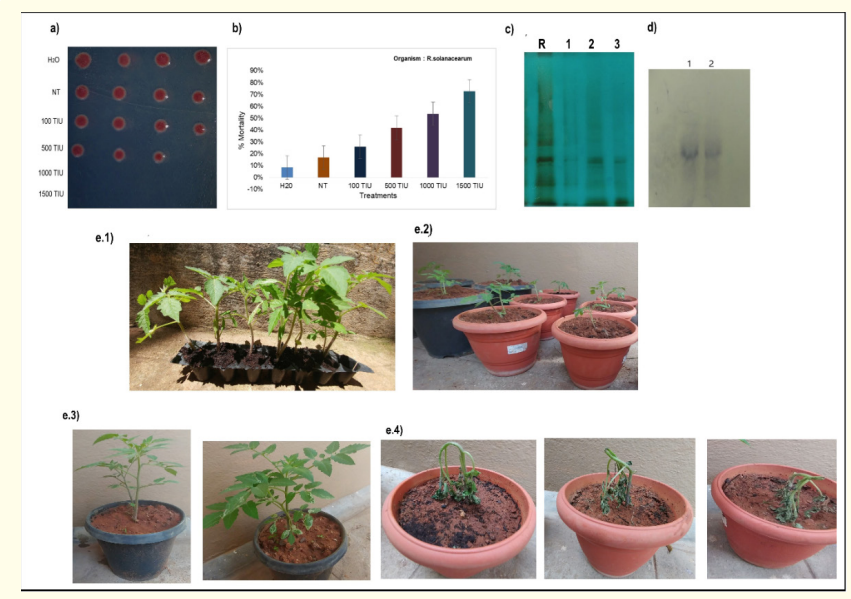

Figure 2: Evaluation of ChTI against $R$. solanacearum. In vitro as well as in vivo evaluation against $R$. solanacearum was carried out. In vitro evaluation was done by serial dilution assay, Different concentrations of ChTI 100 - 1500 TIU was incubated with serially diluted bacterial cells (10-1 - 10-3). MIC is observed to be 100TIU. Water and Non transgenic plant extracts were used as control. b) The above mixture was incubated with Evans blue dye for $2 \mathrm{~h}$ resulting in the correlation of results of serially dilution assay and Evan's blue assay. MIC was recorded at 100TIU with 24\% mortality rate. c) SDS -PAGE visualization of membrane proteins eluted from ChTI-sepharose affinity column. Lane R: membrane proteins before elution used as control, lane 1: Unbound eluted fraction, lane 2 and 3: ChTI bound eluted using 2\% SDS. d) Western blot analysis of ChTI bound eluted fractions with ChTI-IgY. e) Transgenic plants were challenged with $R$. solanacearum 1: Day 1 before inoculation, Non transgenic plants were taken as control. 2: day 3 post inoculation, 3: Transgenic plants at day 15 were plants showed no symptoms of wilt, 4: Non transgenic plants at day 11 were plant almost succumbed to infection. 


\section{ChTI-PLP in-silico docking}

In silico docking analysis was used to study the possible interaction between PLP (chain A) - ChTI. The overall structure consists of 300 amino acid residues. ChTI consists of 5 helices with 4 loop structure. Interaction patterns regarding the conserved residues of domain mlaC (Figure 4) with ChTI was carried out. 8 hydrogen bonds, Lys 124 (A) - Glu 96 and Ser 100; Arg 127 (A) - Arg 19, Arg 48, Glu 42; Asp 131(A) - Arg 12; Asp 151 (A) - Cys 103 at bond distance ranging between 2.12 and 3.22 was observed in this interaction studies (Figure 3).

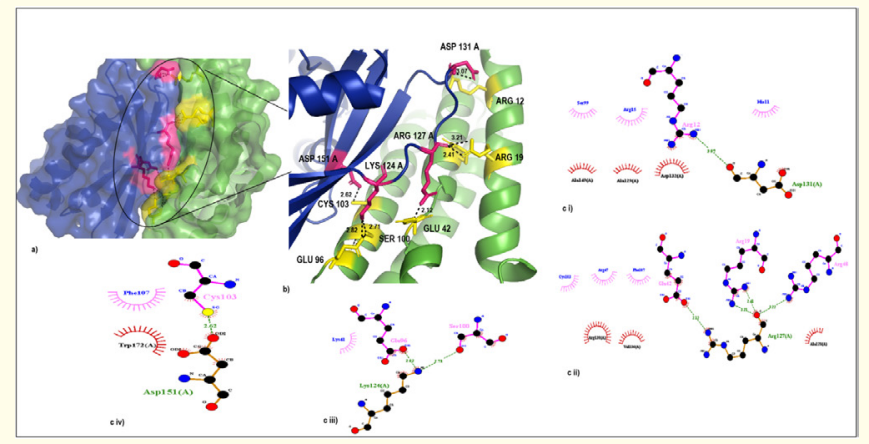

Figure 3: Interaction of ChTI on R. solanacearum membrane proteins. a) Surface view of the interaction between ChTI (Green) and PLP (Blue). b) 3-D visualisation of interaction residues of ChTI (yellow-sticks) and PLP (megenta-sticks). c) 2-D representation of interaction between ChTI and PLP (chain A).

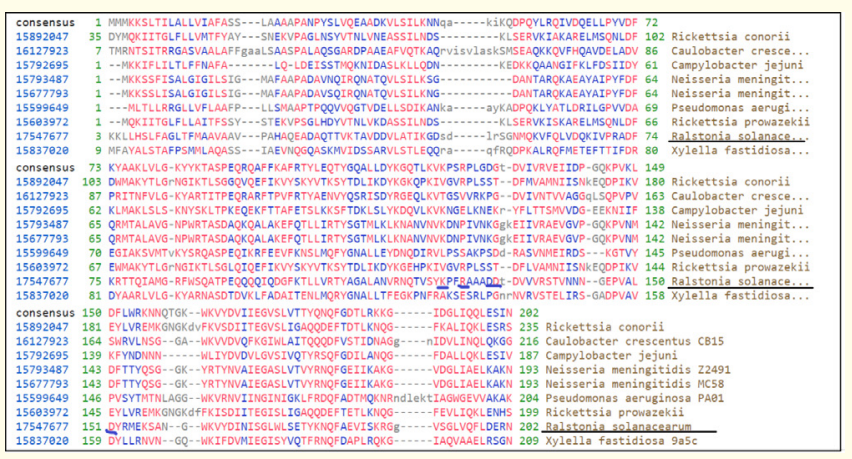

Figure 4: Conserved amino acid residues of mlaC domain. The highlighted residues are predicted to be interacting with ChTI.

\section{ChTI-phospholipid interaction}

The probable interaction of ChTI with Di- Palmitoy-3-Sn-Phosphatidylethanolamine was also carried out the mechanism of ChTI binding to membrane proteins. ChTI amino acid residues: Arg 12, Glu 96, Ser 100, Cys 103 interacted with Asp 131 A, Lys 124 A, Asp
151 A, respectively and Arg 19, Glu 42, Arg 48 with Arg 127A,were involved in the interaction via hydrogen bonding (Figure 5).

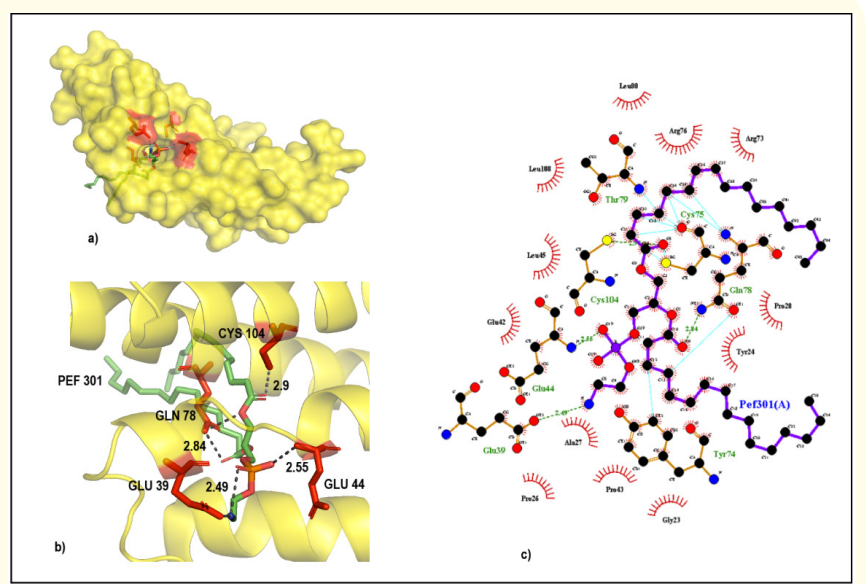

Figure 5: Possible mechanism of action of ChTI and phospholipid. a) Surface view of the interaction between ChTI (Yellow) and PEF (green). b) 3-D visualisation of interaction residues of ChTI (redsticks) and PLP (green-sticks). c) 2-D representation of interaction between ChTI and PEF (chain A).

\section{Discussion}

PIs act as therapeutic intervention of certain microbial infection. These are known as defense molecules in plants and protect them from phytophagous insects and microbes [25-27]. ChTI, $18 \mathrm{kDa}$ thermostable protein inhibits the growth of $E$. coli with an MIC of $0.1 \mathrm{mg} / \mathrm{ml}$ and IC $_{50}$ of $0.8 \mathrm{mg} / \mathrm{ml}$. Studies on bactericidal activity of Coccinia grandis protease inhibitor on Staphylococcus aureus, Bacillus subtilis, E. coli showed MIC of $1 \mathrm{mg} / \mathrm{ml}$ [10]. Thermostable chymotrypsin inhibitor, Potide G inhibited the growth of $S$. aureus, E. coli and Clavibacter michiganense [28]. Trypsin inhibitor isolated from Brassica chinensis seeds showed bactericidal activity against B. subtilis and B. cereus with an $\mathrm{IC}_{50}$ of $236 \mu \mathrm{M}$ and $222 \mu \mathrm{M}$, respectively [29]. Effect of ChTI on $R$. solanacearum showed complete mortality of bacterial cells with IC $_{50}$ of $0.5 \mathrm{mg} / \mathrm{ml}$ and MIC of $0.1 \mathrm{mg} / \mathrm{ml}$. Transgenic plants tested against $R$. solanacearum performed better than the control plants with $80 \%$ survival rate. Dual expression of proteinase inhibitor genes, Sporamin (trypsin inhibitor) and CeCPI (Phytocystatin) in transgenic tobacco plants have conferred resistance to bacterial pathogens Erwinia carotovora and Pythium aphanidermatum [30]. PIs have been conferred with insecticidal and fungicidal activity since their identification and characterization, but not as bactericidal agents. Many AMPs have been reported to act on membrane surface resulting in pore formation followed by leakage of cell contents, resulting in the variation in 
membrane polarization, finally leading to cell mortality [31]. Many AMPs are reported to interact with membrane lipids. Amphiphatic nature and positive charge at physiological $\mathrm{pH}$ make PIs adhere to membrane lipids and the mode of action is yet to be understood.

Binding of membrane proteins to ChTI affinity sepharose column suggest that ChTI interacts with $R$. solanacearum cell membrane (Figure 2c). Phospholipid binding protein from $R$. solanacearum was docked with ChTI. The results predicted that ChTI residues bound to conserved residues of domain mlaC, part of mla operon aiding in shuttling lipid substrates between inner membrane and outer membrane [32]. Screening Acinetobacter baumannii ABC transporter system homologs to the Mla system in $E$. coli showed that the pathogen uses this complex for phospholipid transport from inner membrane to outer membrane [33]. We predict that ChTI binds to this domain, and cause hindrance in biogenesis of lipid membrane resulting in loss of structural integrity of the cell wall leading to cell mortality. Further interaction of ChTI with phospholipid via hydrogen bonding, especially ChTI residue Glu 44 to phosphate group moiety along with other stabilizing interactions with membrane lipid also predicts the masking of the lipid moiety, thus making the substrates unrecognizable to lipid binding proteins.

\section{Conclusion}

The present study led to the identification of proteinase inhibitor gene, ChTI exhibiting bactericidal activity. Transgenic plants expressing these conferred resistance to $R$. solanacearum, one of most devastating pathogens infecting tomato. Affinity column as well as in silico analysis revealed the probable mode of action of ChTI is by binding to bacterial phospholipid binding protein or by making the host membrane phospholipids unrecognizable to these proteins.

\section{Author Contributions}

Dr. Devaraj V.R. , Dr. Theertha Prasad. D conceived and designed the experiments; Ms. Manushree. V, performed the experiments. Manushree $V$ wrote the manuscript. All authors reviewed the manuscript.

\section{Declaration of Interest}

This manuscript has not been submitted to, nor is under review at, another journal or other publishing venue.

\section{Bibliography}

1. Ingmer $\mathrm{H}$ and Brondsted L. "Proteases in bacterial pathogenesis". Research in Microbiology 160 (2009): 704-710.
2. Yu GL., et al. "Arabidopsis mutations at the RPS2 locus result in loss of resistance to Pseudomonas syringae strains expressing the avirulence gene avrRpt2". Molecular Plant-Microbe Interactions 6 (1993): 434- 443.

3. Guttman DS and Greenberg JT. "Functional analysis of the type III effectors AvrRpt2 and AvrRpm1 of Pseudomonas syringae with the use of a single-copy genomic integration system". Molecular Plant-Microbe Interactions 14 (2001): 145-155.

4. Bardoel BW., et al. "Pseudomonas evades immune recognition of flagellin in both mammals and plants". PLOS Pathogens 7 (2011): e1002206.

5. Feng T., et al. "Characterization of an extensin-modifying metalloprotease: $\mathrm{N}$-terminal processing and substrate cleavage pattern of Pectobacterium carotovorum Prt1". Applied Microbiology and Biotechnology 98 (2014): 10077-10089.

6. Ustun S., et al. "The Xanthomonas campestris type III effector XopJ targets the host cell proteasome to suppress salicylic-acid mediated plant defence". PLOS Pathogens 9 (2013): e1003427.

7. Ustun S., et al. "HopZ4 from Pseudomonas syringae, a member of the HopZ type III effector family from the YopJ superfamily, inhibits the proteasome in plants". Molecular Plant-Microbe Interactions 27 (2014): 611-623.

8. Gimenez-Ibanez S., et al. "The bacterial effector HopX1 targets JAZ transcriptional repressors to activate jasmonate signaling and promote infection in Arabidopsis". PLOS Biology 12 (2014): e1001792.

9. Nawrot R., et al. "Plant antimicrobial peptides". Folia Microbiologica 59 (2014): 181-196.

10. Kumar P., et al. "Antimicrobial Peptides: Diversity, Mechanism of Action and Strategies to Improve the Activity and Biocompatibility In Vivo". Biomolecules 19 (2018): 8.

11. Satheesh LP and Murugan K. "Antimicrobial activity of protease inhibitors from leaves of Coccinia grandis (L.) Voigt". Indian Journal of Experimental Biology 49 (2011): 366-374.

12. Rakashanda S., et al. "Antibacterial activity of a trypsin-chymotrypsin-elastase inhibitor isolated from Lavatera cashmeriana seeds". The Journal of Animal and Plant Sciences 22 (2012): 983-986. 
13. Shamsi T and Fatima S. "Protease Inhibitors as Antibiotics". Journal of Pharmaceutical Sciences 3 (2016): 131-137.

14. Zasheva D and Lyudmila S. "Antitumour potential of plant protease inhibitors". Journal 'Genetics and Plant Physiology 7 (2017): 147-159.

15. Souza LdC., et al. "Effects of an Anticarcinogenic Bowman-Birk Protease Inhibitor on Purified 20S Proteasome and MCF-7 Breast Cancer Cells". PLoS One 9 (2014): e86600.

16. Srikanth $\mathrm{S}$ and Chen Z. "Plant protease inhibitors in therapeutics-focus on cancer therapy". Frontiers in Pharmacology 7 (2016): 470.

17. Fear G., et al. "Protease inhibitors and their peptidomimetic derivatives as potential drugs". Pharmacology and Therapeutics 113 (2007): 354-368.

18. Bijina Sreeja Chellappan., et al. "Protease inhibitor from Moringa oleifera with potential for use as therapeutic drug and as seafood preservative". Saudi Journal of Biological Sciences 18 (2011): 273-281.

19. Bhattacherjee C., et al. "Purification of a trypsin inhibitor from Cocculus hirsutus and identification of its biological activity". Journal of Crop Science and Biotechnology 12 (2010): 253-260.

20. Manushree V., et al. "Expression of Cocculus hirsutus trypsin inhibitor promotes endogenous defensive response against Helicoverpa armigera and enhanced levels of antioxidants". African Journal of Plant Science 14 (2020): 65-82.

21. March SC., et al. "A simplified method for cyanogen bromide activation of agarose for affinity chromatography". Analytical Biochemistry 60 (1974): 149-152.

22. Yan Y., et al. "HDOCK: a web server for protein-protein and protein-DNA/RNA docking based on a hybrid strategy". Nucleic Acids Research 45 (2017): 365-373.

23. Laskowski RA and Swindells MB. "LigPlot+: multiple ligandprotein interaction diagrams for drug discovery". Journal of Chemical Information and Modeling 51 (2011): 2778-2786.

24. DeLano WL. "Pymol: An open-source molecular graphics tool". CCP4 Newsletter on Protein Crystallography 40 (2002): 82-92.

25. Kim SG., et al. "Evaluation of Resistance to Ralstonia solanacearum in Tomato Genetic Resources at Seedling Stage". The Plant Pathology Journal 32 (2016): 58-64.
26. I Arulpandi and R Sangeetha. "Antibacterial Activity of Fistulin: A Protease Inhibitor Purified from the Leaves of Cassia fistula". International Scholarly Research Network ISRN Pharmaceutics (2012): 584073.

27. Patrícia MGP., et al. "Protease inhibitors from plants: Biotechnological insights with emphasis on their effects on microbial pathogens" (2013).

28. Kim JY., et al. "Protease inhibitors from plants with antimicrobial activity". International Journal of Molecular Sciences 10 (2009): 2860-2872.

29. Ngai P and $\mathrm{Ng}, \mathrm{T}$. "A napin-like polypeptide from dwarf Chinese white cabbage seeds with translation-inhibitory, trypsininhibitory, and antibacterial activities". Peptides 25 (2004): 171-176.

30. Senthilkumar R., et al. "Genetically pyramiding protease-inhibitor genes for dual broad-spectrum resistance against insect and phytopathogens in transgenic tobacco". Plant Biotechnology Journal 8 (2010): 65-75.

31. Brogden Kim. "Antimicrobial peptides: Pore formers or metabolic inhibitors in bacteria?" Nature Reviews Microbiology 3 (2005): 238-250.

32. Ekiert DC., et al. "Architectures of Lipid Transport Systems for the Bacterial Outer Membrane". Cell 169 (2017): 273-285.

33. Kamischke C., et al. "The Acinetobacter baumannii Mla system and glycerophospholipid transport to the outer membrane". Elife 8 (2019): e40171.

\section{Assets from publication with us}

- Prompt Acknowledgement after receiving the article

- Thorough Double blinded peer review

- Rapid Publication

- Issue of Publication Certificate

- High visibility of your Published work

Website: https://www.actascientific.com/

Submit Article: https://www.actascientific.com/submission.php Email us: editor@actascientific.com

Contact us: +919182824667 